\title{
Building an ontological modeling mechanism for virtual cities
}

Luis Casillas

Computer Science Department, University of Guadalajara, Mexico

luis.casillas@cucei.udg.mx

Gilberto Vargas

Computer Science Department, University of Guadalajara, Mexico

tachoguitar@gmail.com

Miguel Lares

Computer Science Department, University of Guadalajara, Mexico

c.code.jp@gmail.com

Abstract: Modeling of cities is certainly a challenge. Most of this complexity is caused by the significant number of variables, as well as the vast manifestation for their ranks. Diverse efforts have been conducted by different researchers, in order to achieve powerful representations. Some of these efforts are aimed at graphical representation, some others are aimed at functionality. Present effort is aimed at the scaffolding support for the representation and, eventually, functionality of virtual cities. Such infrastructure would support current and future efforts devoted to populating virtual cities with agents showing different behaviors and roles. These 
agents would be active and concrete elements in cities, such as pedestrians, cars or drivers, and some others would be dynamic synthetic-elements, such as traffic lights or drawbridges. These agents will populate the city model and manifest in future efforts from this research; current effort is mainly focused in the production of cities' infrastructure. The generation and representation of a virtual city is, per se, a significant challenge. This paper focuses in such challenge.

key words: Ontology, Knowledge Management, Virtual City, Simulation, Voronoidiagram, Delaunay-triangulation.

\section{Construcción de un mecanismo de modelado ontológico para ciudades virtuales}

Resumen: El modelado de ciudades es ciertamente desafiante. La mayor causa de esta complejidad es el significativo número de variables, así como la vastedad en la manifestación de sus rangos. Diversos esfuerzos han sido realizados por diferentes investigadores con el fin de lograr representaciones contundentes. Algunos de estos esfuerzos se han orientado a la representación gráfica y algunos otros a la funcionalidad. El presente esfuerzo está orientado al andamiaje que soporta la representación $y$, eventualmente, la funcionalidad de ciudades virtuales. Tal infraestructura soportaría los esfuerzos actuales y futuros dedicados a poblar la ciudades virtuales con agentes que muestren diferentes comportamientos y roles. Estos agentes serían elementos activos y concretos en la ciudades, tales como automóviles o conductores, y otros serían elementos sintéticos - dinámicos tales como semáforos o puentes levadizos. Estos agentes poblarán el modelo de ciudad y se manifestarán en futuros emprendimientos de esta misma investigación; el trabajo actual se enfoca principalmente a la producción de la infraestructura de la ciudad. La generación y representación de la ciudad virtual es, per se, un esfuerzo desafiante. Este artículo se enfoca en tal esfuerzo.

Palabras clave: Ontología, Gestión del Conocimiento, Ciudad Virtual, Simulación, Diagrama de Voronoi, Triangulación de Delaunay. 


\section{Introduction}

There are diverse challenges when trying to model virtual cities, due the variety of actors in real cities. Regarding real cities, most of these actors are understood as city elements. These elements are, in most of cases, disabled to change the city structure, its topology or even its functionality. Nevertheless, cities have some active elements aimed at modifying the city: municipalities, urban-planners, realestate developers, and even natural events such as earthquakes, hurricanes, twisters, etc. These active elements eventually would produce deep-impact effects on mobility for citizens and/or vehicles. Because of the lack of information from real cities, it is difficult to grasp options and tools to simulate the real stress and the whole phenomena in a big city.

The present effort is aimed at producing an ontological structure for representing virtual cities. The primary motivation for this effort, is the lack of updated data, and in most cases the lack of data at all. Our approach is inspired by similar efforts as (Davies, Duke, \& Sure, 2004), but the proposal in this paper is based on real communities instead of web sources. Most of cities are not enabled to collect every data produced by every single element in the city. Some cities are enabled to collect data from diverse phenomena happening inside the city boundaries, nevertheless lots of signaling and corresponding data is simply lost. Hence, every analysis performed over those collected data will lack of elements that somehow produce an influence. It is rather difficult to find out patterns when required data is not enough.

The urban model of big cities need to be often changed. Unfortunately such changes will not be made as frequently as required. But even when changes were required by city's inhabitants, such modifications usually face enormous resistance from social, economic, and political groups in city. When considering upgrades to the urban environments it is needed to know what the best ways to improve the urban planning are. Throughout an effort as the presented in this paper, there is going to be an enabled tool to produce, manage and even control diverse aspects of virtual cities; in order to have a synthetic representation of a city. The main goal of this research is to find out ways for simulating virtual cities, as well as artificial 
agents inside, which will learn the best practices to meet their needs. Thus, this paper presents the stage devoted to produce a description for logical definitions, as well as the geometrical algorithms to generate the physical corpus of cities.

\section{Related Work}

Due to complexity bound to cities' emulation, because the number of variables and their wide ranges, several efforts have been done along the time. Such aspect is deeply reviewed by (Gandy, 2005). Some of the tools for city emulation are focused on the graphical representation, and some others focus on inner structures devoted to support the model's functionality. The modeling mechanism presented in this paper, is somehow focused on the structural approach; according to the following review.

Due to complexity bound to cities' emulation, because the number of variables and their wide ranges, several efforts have been done along the time. Such aspect is deeply reviewed by (Gandy, 2005). Some of the tools for city emulation are focused on the graphical representation, and some others focus on inner structures devoted to support the model's functionality. The modeling mechanism presented in this paper, is somehow focused on the structural approach; according to the following review.

Based on the previous statement, despite the vast quantity of tools to help urban modeling, there is a lack of tools devoted to simulate study-cases focusing in city operation, instead of its mere visualization; since modern tools frequently focus in 3D simulation and do not have enough power to deal with issues regarding how chaotic and erratic a real city is.

Based on the previous statement, despite the vast quantity of tools to help urban modeling, there is a lack of tools devoted to simulate study-cases focusing in city operation, instead of its mere visualization; since modern tools frequently focus in 3D simulation and do not have enough power to deal with issues regarding how chaotic and erratic a real city is.

This first stage of this city simulator is aimed at the representation for the logic information from the city and the geometrical algorithms to generate pseudo- 
random cities. We are working from inside to out. A problem faced by this project, is the availability of data and information coming from real cities in the world. When data and information exist: they are not publicly available, they are not enough, they are not precise, they are polluted, and etcetera. In the rest of cases there are neither data nor information available. To deal with this annoying issue, we have worked in a sophisticated algorithm that is able to produce, as an output, a complex network which represents a possible structure for a virtual city. Such algorithm possess a series of parameters aimed at affecting the structure, organization and, even, operation of the virtual representation of the city. By these controlling mechanisms over cities' construction, the virtual representation of cities keeps as chaotic as real city could be.

Based on (Fortune, 1987), our algorithm approach has an inspiration from Voronoi's diagrams, in order to produce chaotic polygons. Such mesh of polygons represents an ensemble of regions, such as diverse regions and spaces inside a city. Then, every region is populated with streets. Streets population is produced by the creation of a grid inside every polygon (region). Avenues were made with a fractal algorithm, inspired in the efforts made by Parish \& Müller (2001), where they used the same algorithm; although these authors had a geographical structure as an input, and an additional algorithm for building a city using L-Systems. Another interesting aspects from Parish \& Müller (2001), is that they also divided the blocks on houses and generated a 3D view of the whole city, the focused on the map view as an output, we will focus on the information representation. The effort performed in the present study is not aimed at producing a complex 3D view as (Döllner \& Hagedorn, 2007), instead this work is aimed at the inner handling of structures and models representing the city. The work (Courtat, Gloaguen, \& Douady, 2010) models up a novel understanding for cities' virtual representation. Throughout the use hypergraphs, authors were able to represent each street as hyper-relationship between a set of segments. As proposed in (Ge, Meng, Cao, Qiu, \& Huang, 2014), authors used a different approach for simulation, which consists in giving a treatment as a macro level where social events and statistics are simulated instead of micro events related to population gender, age, occupation, etc. Our 
proposal is also based on generating artificially sets of data, which replaces the absences of real data from unsupervised cities.

\section{Representing knowledge from cities}

There is a confusion regarding what is, in fact, knowledge. This is caused by the resistance offered by the concept "knowledge" itself to be defined. A practical approach to solve the emerging complexity regarding knowledge definition, is to visualize signals from environment as data. Such data, signals from environment, are paired with descriptions stored in brains. When pairing is successfully mated with experience, stored in brains, an amount of information is release. This information is the explanation given by observer to signal retrieved. Hence, the experience is the catalyzing agent for signals processing. This experience could be understood as knowledge. As explained in (Casillas, Daradoumis, \& Caballé, 2013).

Every phenomenon, surrounding us, could be understood and dealt as an amount of knowledge. Knowledge includes a passive portion, made by data and information regarding the phenomenon; and an active portion, made by functionality and behaviors shown by actors in observed phenomenon. This passive/active composition is the most interesting quality of knowledge. Both aspects are bound and deeply mixed in knowledge. A city is actually a phenomenon susceptible of knowledge description. Cities mix passive and active elements.

In order to fulfill the challenging task of city modeling, from the approach presented in previous paragraph, our proposal has been supported by a powerful tool: Protègè . This instrument implements a series of services and machineries aimed at producing enriched models for reality. Protégé's is a plug-in architecture which could be adapted to build both simple and complex ontology-based applications. Developers are enabled to integrate the output of Protégé with rule systems or other problem solvers to construct a wide range of intelligent systems.

Gruber (1993) had originally defined a highly cited notion for an ontology as an "explicit specification of a conceptualization". An ontology behaves as a bridge 
between knowledge representation and the corresponding information management. It is frequent to use semantic networks as a mechanism to model up ontologies. The research effort presented in this work, focuses in three kinds of aspects in order to represent a city. Figure 1 shows this preliminary decomposition Thing

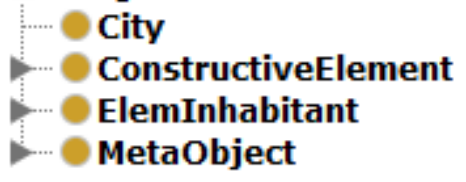

Figura 1. Main knowledge categories for city representation

\subsection{Constructive elements}

This knowledge category tries to represent the awareness regarding physical elements in a city, such as: blocks, cross-intersections, highways, streets, bridges, etc. by classifying them in two subclasses: active and passive elements. Figure 2 sketches the corresponding decomposition for these active and passive elements, involving all possible/regarded actors in nowadays cities. 


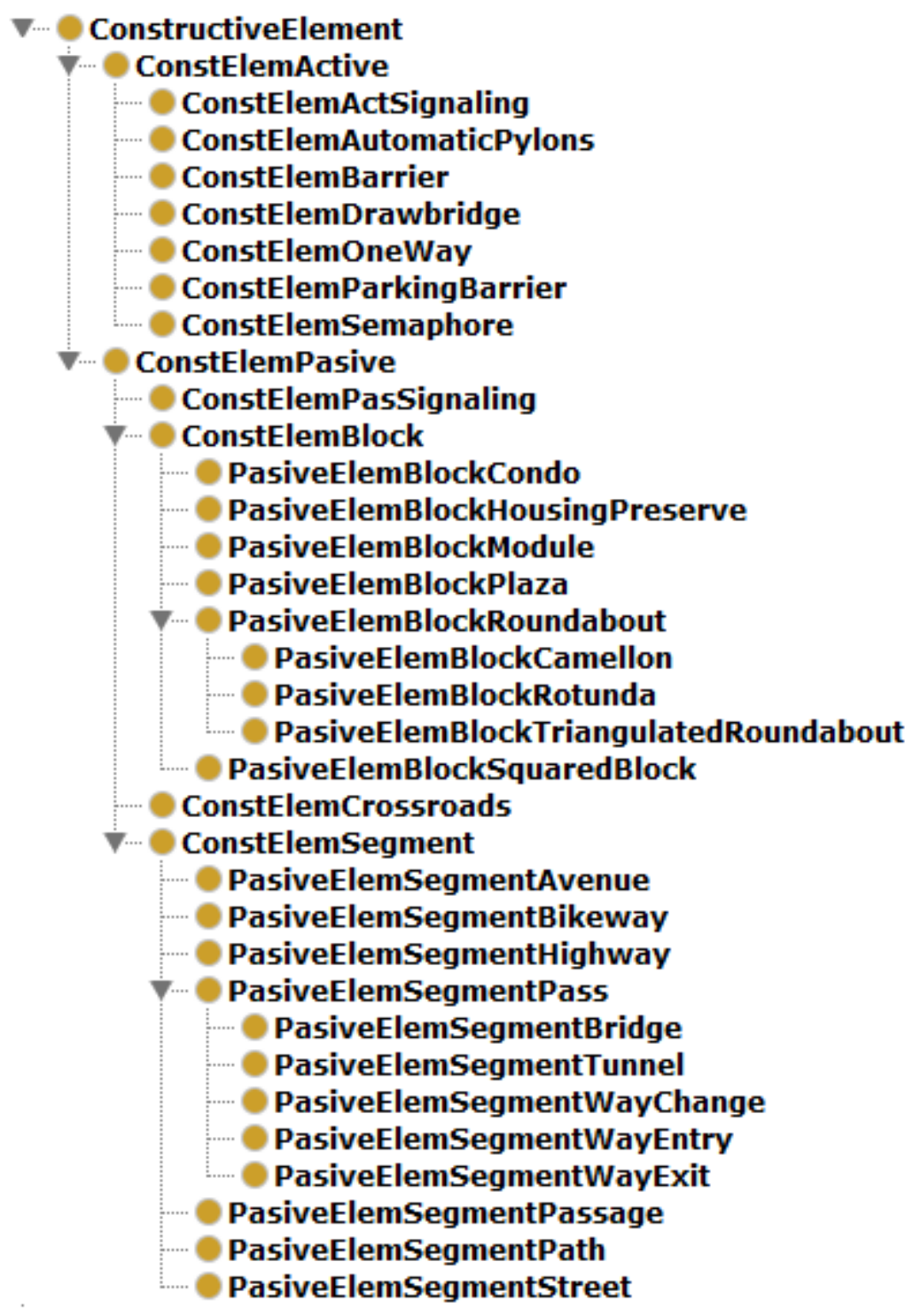

Figura 2. Taxonomical decomposition for the Constructive Element aspect from cities' representation proposed. Includes the corresponding decomposition for active and passive elements.

\subsection{Inhabitant elements}

While some other researchers reduce the domain ontology about the inhabitants in a city (Zhai, Wang, \& Lv, 2008), our ontology tries to be closer to the real manifestation of cities by allowing pedestrians to move around the city. Citizens could eventually move through vehicles as: car, bus, bicycle, train, and etcetera. 
Besides, our model for cities is enabled to include other non-regular inhabitants. Due to complexity of these knowledge categories, the knowledge decomposition analysis will be made by sections. Figure 3 sketches a preliminary decomposition of the inhabitant aspect. Reader is invited to admit our novel approach for inhabitants, including some unalive entities.

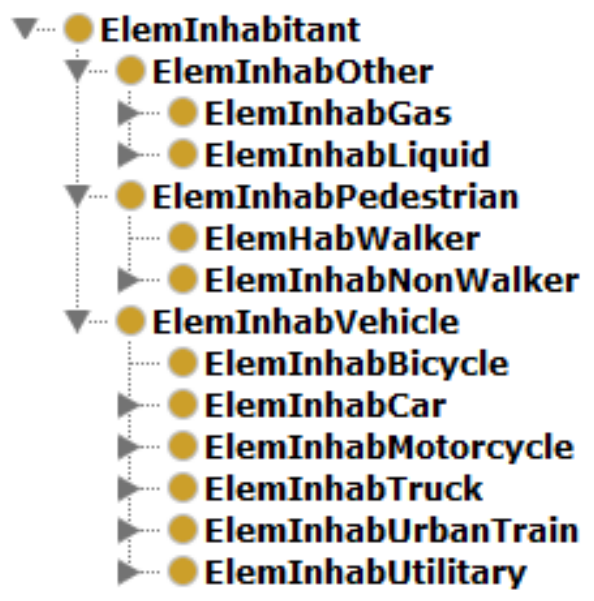

Figura 3. Taxonomical decomposition for the Inhabitant Element aspect from cities' representation proposed. Includes the corresponding decomposition for

Pedestrian, Vehicle and Other inhabitants in the city.

Regarding pedestrian inhabitants category, there are two subcategories: walker and non-walker. The case of walker refers to humans walking or running on their own feet. The non-walker case contains different situations of humans moving on certain mechanisms or artifacts allowing slow-speed mobility among pedestrians. Figure 4 shows a decomposition of this specific subcategory.

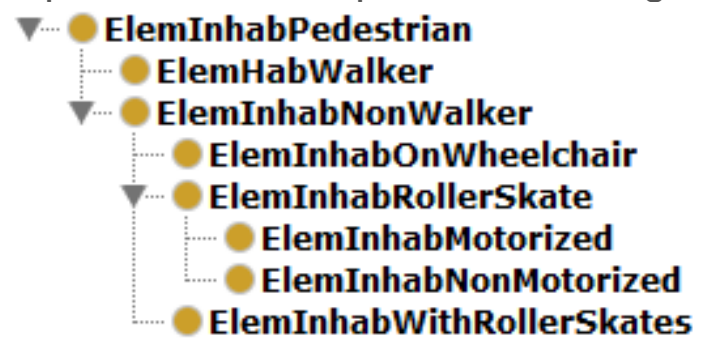

Figura 4. Taxonomical decomposition for the Pedestrian Inhabitant Element aspect from cities' representation proposed. Includes the corresponding decomposition for Walker and Non-Walker inhabitants in the city. 
The vehicle category is actually and that could be moot. Nevertheless, vehicle al inhabitants in a city. Of course, they have no conscience or desires. Vehicles are unaware of their roles in the city, but they in fact have roles. Hence, they were considered as inhabitants of a city. Figure 5 models up a sketch of the vehicle's decomposition for our city ontology. 


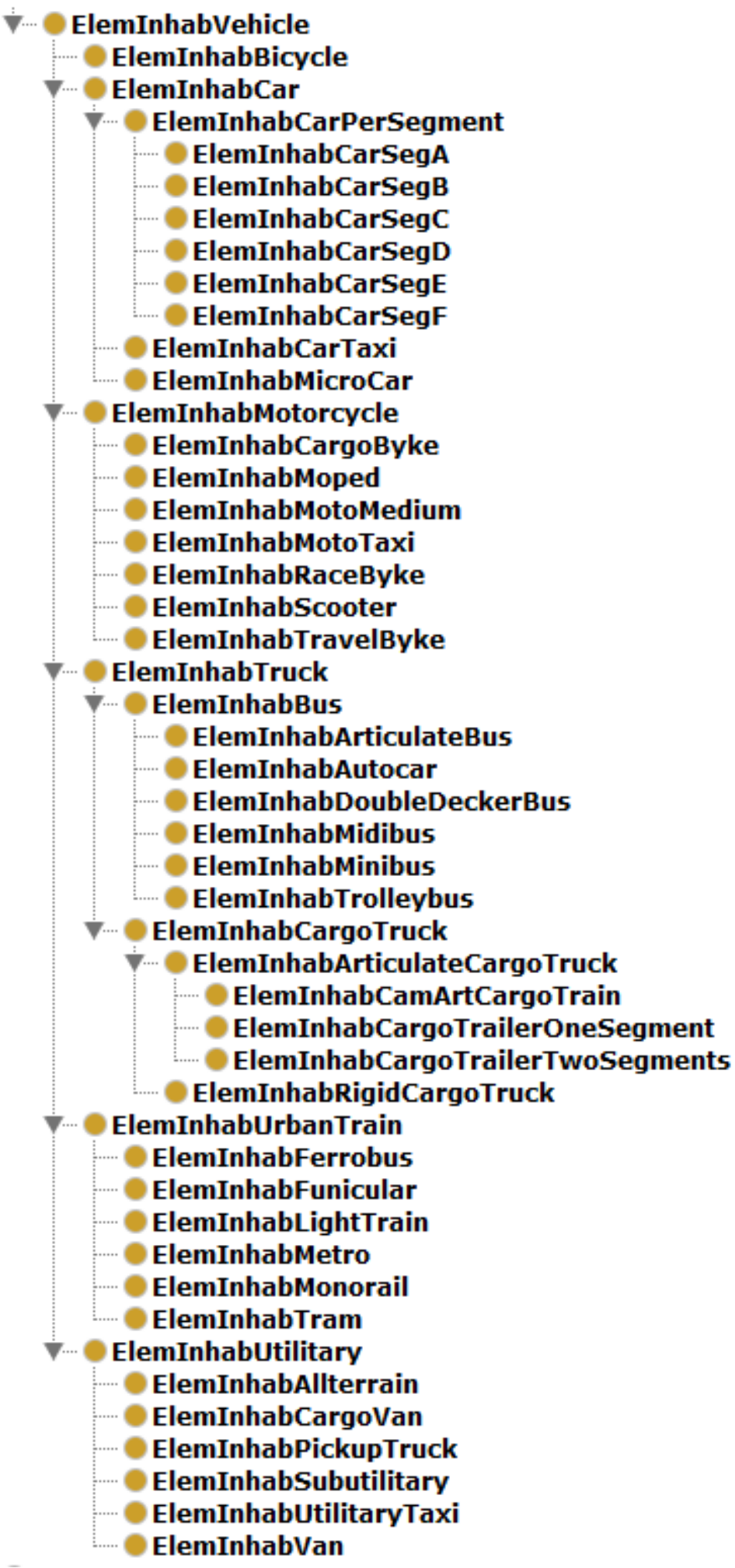

Figura 5. Taxonomical decomposition for the Vehicle Inhabitant Element aspect from cities' representation proposed. Includes the corresponding decomposition for 
Bicycle, Car, Motorcycle, Truck, Urban Train and Utilitarian cases of inhabitants in the city.

Another innovative aspect in our proposal, is the presence of the "Other" category regarding inhabitants in the city. Pedestrians and vehicles have been already considered in the ontology, but our team considered useful to have another kind of inhabitant. Of course, there could be unlimited cases of inhabitants in a city; even some cases unknown for the authors of this work. This is not the goal of the "other" category for inhabitants. The other category is composed by unanimated elements, which are present in a city and produce expected and unexpected effects. It is mainly represented by liquids and gases. This is a strong aspect of our ontology, which considers contamination, rain, raw sewage, leaks, etc. since those elements may be dangerous to society and lead to accidents in many cases they are not considered during cities synthetic representation. Figure 6 shows a decomposition of such category into liquid and gas subcategories.

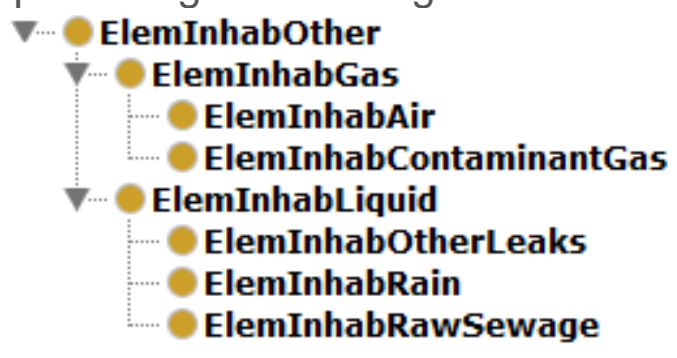

Figura 6. Taxonomical decomposition for the Other Inhabitant Element aspect from cities' representation proposed. Includes the corresponding decomposition for Liquid and Gas cases of inhabitants in the city.

\subsection{Meta Objects}

Beyond the analysis presented up to the moment, we considered as important an extra branching regarding the city ontology. This branch would contain all the awareness regarding interaction, control, description, operation, etc. of city elements regarded in the ontology description. This extra branch has been named as meta-objects and refers to all information describing all the aspects and 
categories in our ontology for cities' representation. Figure 7 presents the elements included in such description mechanism. 


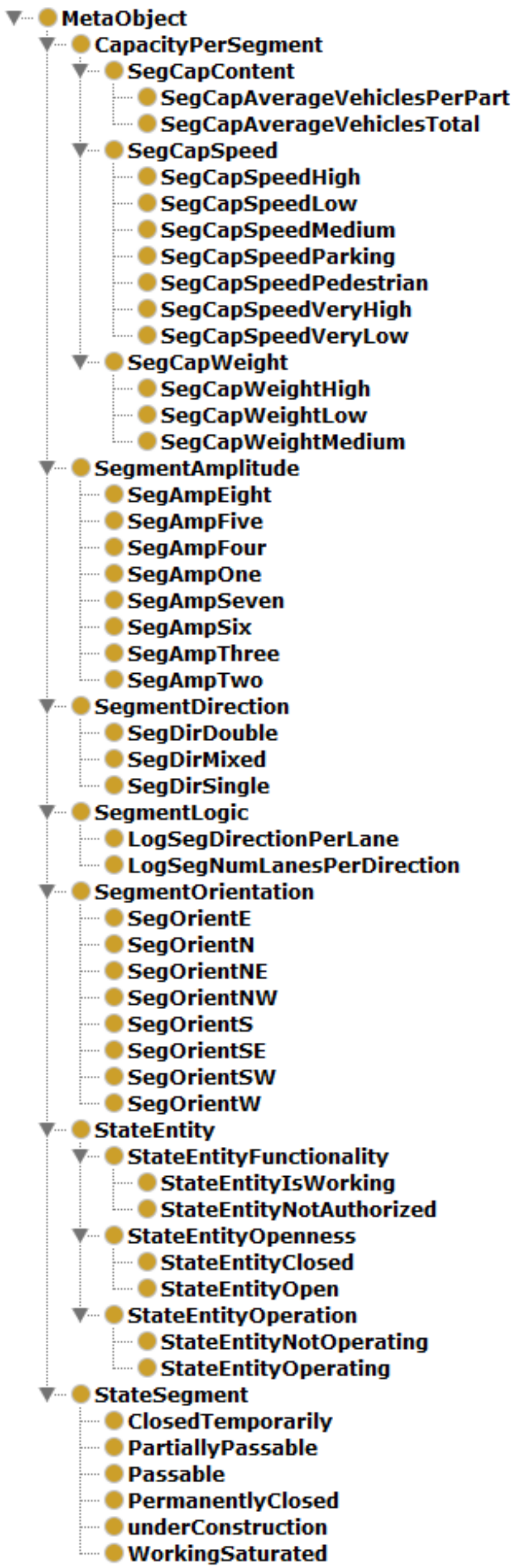


Figura 7. Taxonomical decomposition for the Meta Objects aspect from cities' representation proposed. Contains special classes designated to manage and/or handle diverse operation, control and interaction involving city aspects previously analyzed.

\section{City generation}

Once the ontology has been defined, we focused on the mechanisms enabling the generation of the city. As mentioned before in this work, it is not always possible to have real data or information from cities. Hence, our efforts were aimed at producing the frame of streets and avenues conforming the city's regions. By producing an algorithm enabled to create the city frame. This algorithm could reply to the question: "how can we build streets in a chaotic way but with some sort of regular patterns, which make sense as in real cities?" We found that Voronoi diagrams could help to solve problem, as long as we fix an ensemble with other algorithms.

A Voronoi diagram is a partition of an infinite plane that considers a set of points $P$ to calculate some inner polygons called "voronoi regions", each point is related to one region. Regions are defined as the set of points $\mathrm{S}$ that are closest to $\mathrm{Pi}$ for all the points in $\mathrm{P}$. The most recommended strategy to produce a Voronoi diagram is the sweep line algorithm of Steve Fortune (1987), which has an $O(n \log n)$ complexity. In order to create a Voronoi diagram, the Delaunay triangulation is calculated. The next step is getting the regions from such triangulation. These regions can be understood as city colonies. Figure 8 shows the results of running Fortune's Algorithm. 


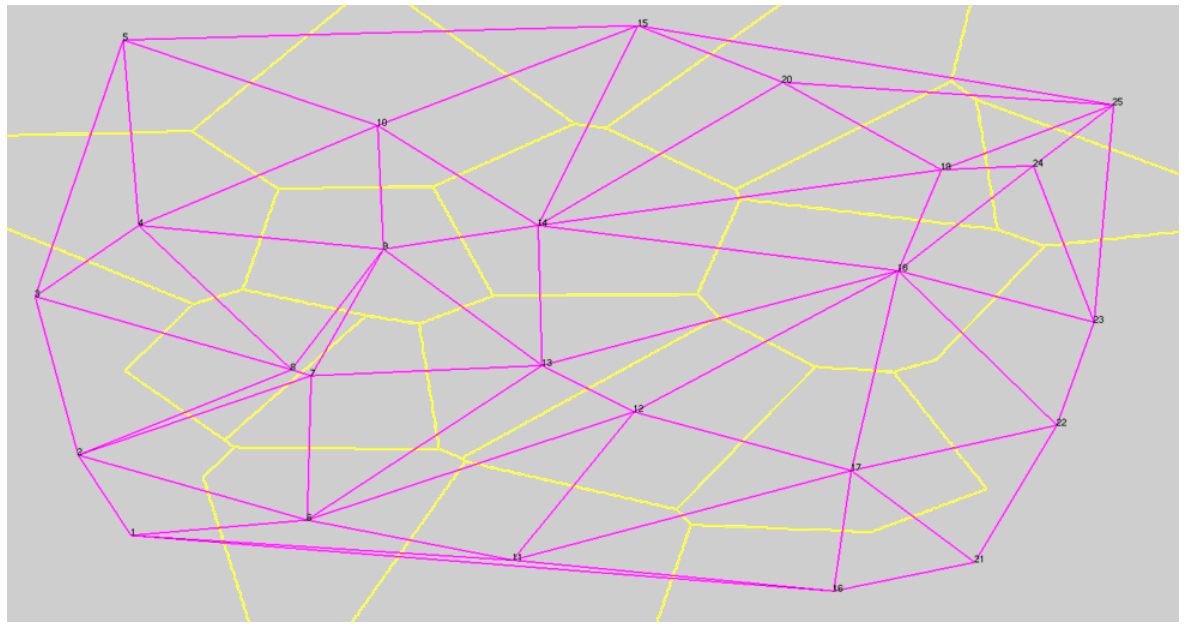

Figura 8. After running Fortune's Algorithm, these are the regions created. In the figure, purple lines represent the Delaunay triangulation and yellow lines contain the voronoi regions.

Once regions have been generated, they should be populated with streets. There could be used several mechanisms in order to create streets inside every region; from regular squared distribution, up to complex fractal algorithms to produce branches. At this point of the project, regions will be populated with streets using rectangles. In order to avoid a squared and predictable distribution of streets among regions, every polygon representing a region is randomly rotated and then filled up with rectangles. Figure 9 shows an example of this effort for populating regions with streets. 


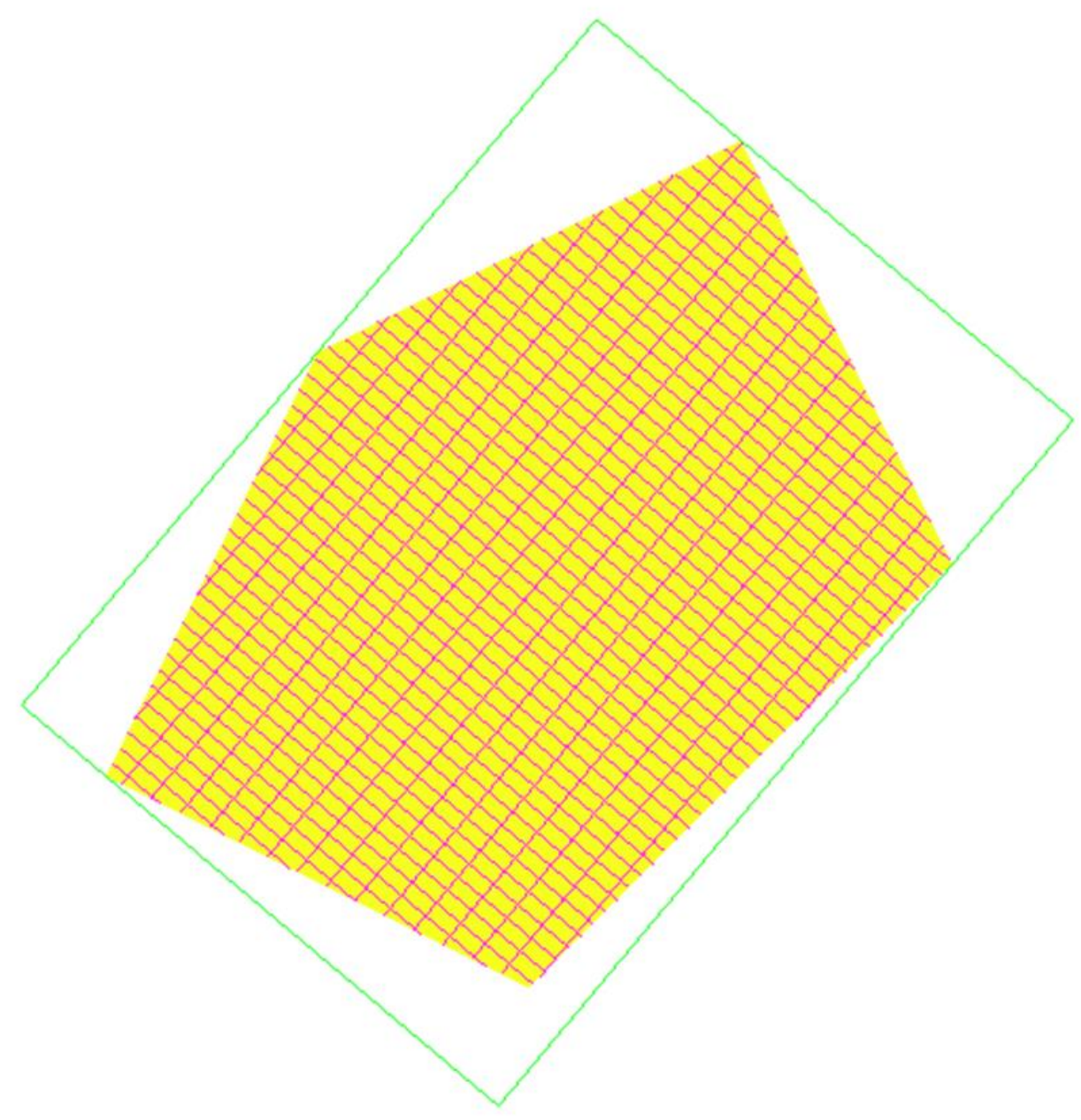

Figura 9. An example of populating a polygon (city region) with rectangles, which represent the inner streets. The region was randomly rotated and populated with rectangles, producing the inner elements.

The process is repeated over and over, involving every voronoi region created. Thus, all map regions are populated, producing an non-regular grid. Such structure clearly resembles a real city map. Figure 10 shows such results. Reader should consider that there are different parameters for producing these elements, hence the regions' size as well as the populating strategies may imply into different city structures and organization. 


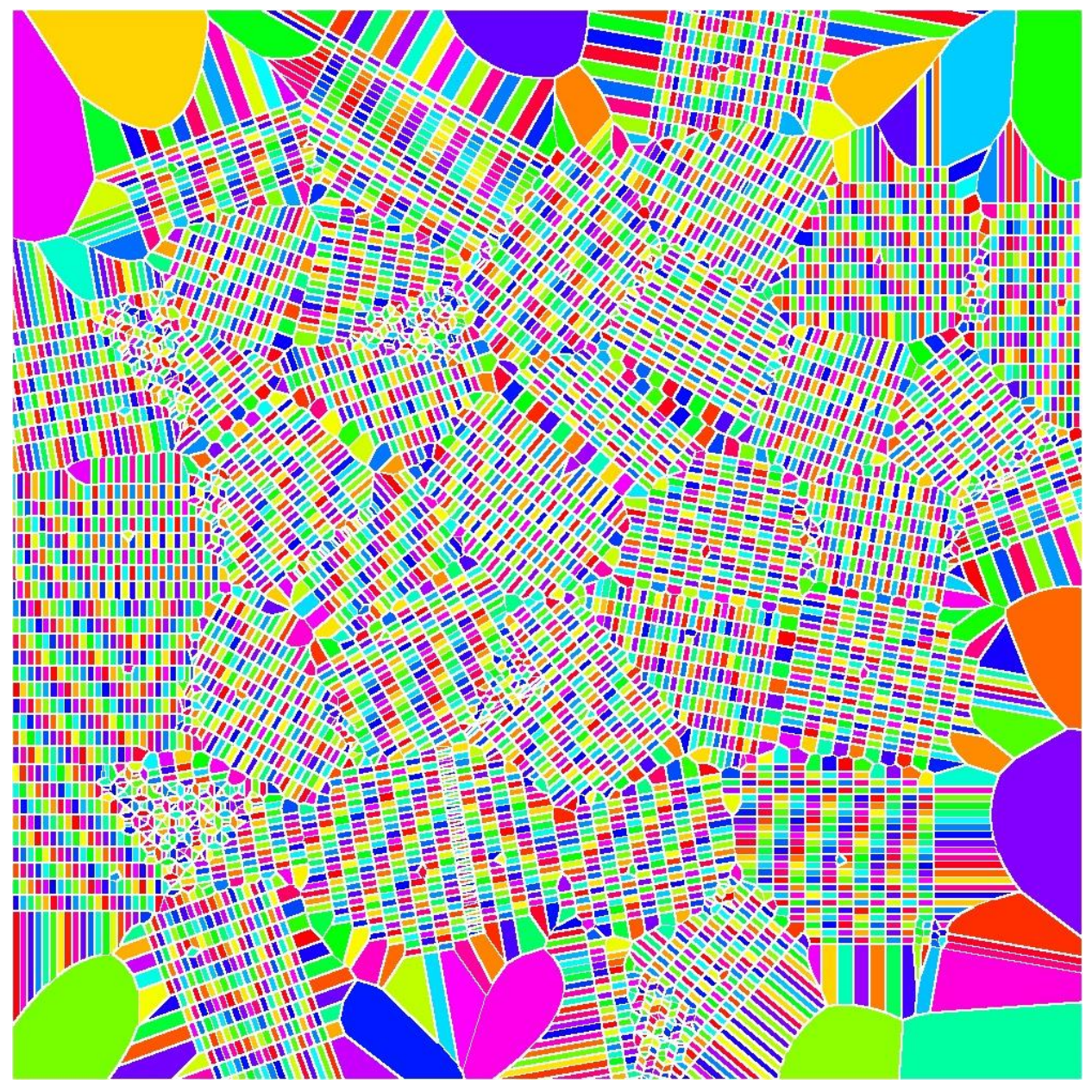

Figura 10. When all regions in map are populated throughout the random rotation algorithm and rectangle fill up, suddenly results a map resembling a real city. Although the maps resulting from the previous algorithm look alike cities, they are not clearly designed to not be traveled by car. These cities are similar, somehow, to old villages or cities from XVIII century. Nowadays cities require some wide streets, long enough to divide the city and allow traveling long distances easily. Traveling by car or another long range vehicles. Hence, an additional mechanism was created, in order to generate something like avenues. These artificial avenues should not be straight lines, instead they would be rough broken lines; as they are in real world.

The first step consists in creating a straight line, and then calculate the middle point, after that we move the middle point and randomly create an angle; keeping it in the bisector. Such mechanism is repeated to every resulting line from applying 
middle point. Just like a fractal generation: same rule recursively. Figure 11 contains an example of this line splitting.

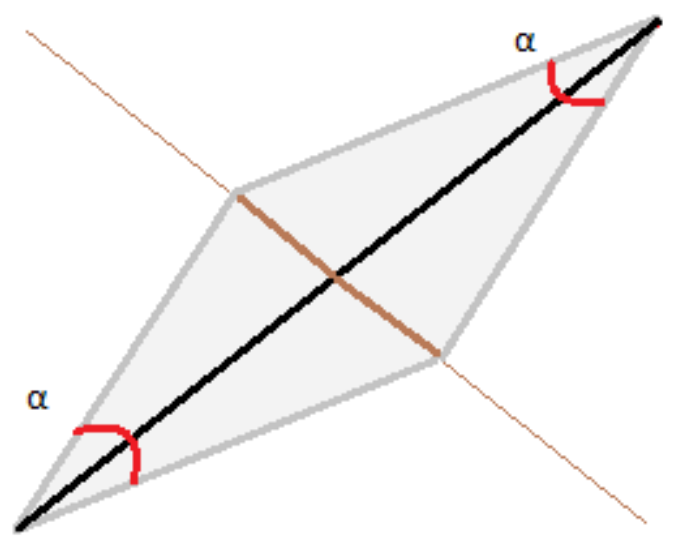

Figura 11. Line split considering angle $\alpha$ for denoting the maximum deviation After applying some iterations over the original line, a virtual representation from an avenue has been created. Please, see figure 12 containing the evolution process for an artificial avenue using the described algorithm.

\begin{tabular}{|l|l|l|}
\hline & & \\
\hline$\gamma$ & & \\
\hline$\gamma$ & & \\
\hline & & \\
\hline
\end{tabular}

Figura 12. Evolution process for the generation of an artificial avenue, by the use of the bisector and randomly angling on lines.

Artificial avenues are integrated into the model and there is an impressive improvement regarding city configuration. The model suddenly acquires an organization which mimics real modern cities. It is possible to verify such aspect in figure 13. 
The city generation algorithm has some parameters as input:

- Size of the city

- Size of the grid for the random points

- Number of vertical avenues

- Number of horizontal avenues

- Angle for the roughness of the avenues

- Size of the blocks

These elements can be manage in order to produce different city's topologies.

\section{Putting all together}

On the one hand there is an ontological model enabled to represent cities, on the other hand there is a mechanism enabled to produce the geometric representation for a city. The city generation mechanism has been also enabled to produce the ontological representation for the generated city. This simple action enables the possibility to store the city and recovering it from secondary memory, giving persistence to the whole model.

The main goal of these research effort is to produce synthetic cities, which can be populated with diverse agents from different categories. Current paper focuses on the definition of the city ontological model and the very production of the city through geometrical analysis. Future efforts in this research line will focus in the agents' definition and their insertion in the synthetic city. This is certainly a complex research effort requiring different stages in order to fulfill all requirements. 


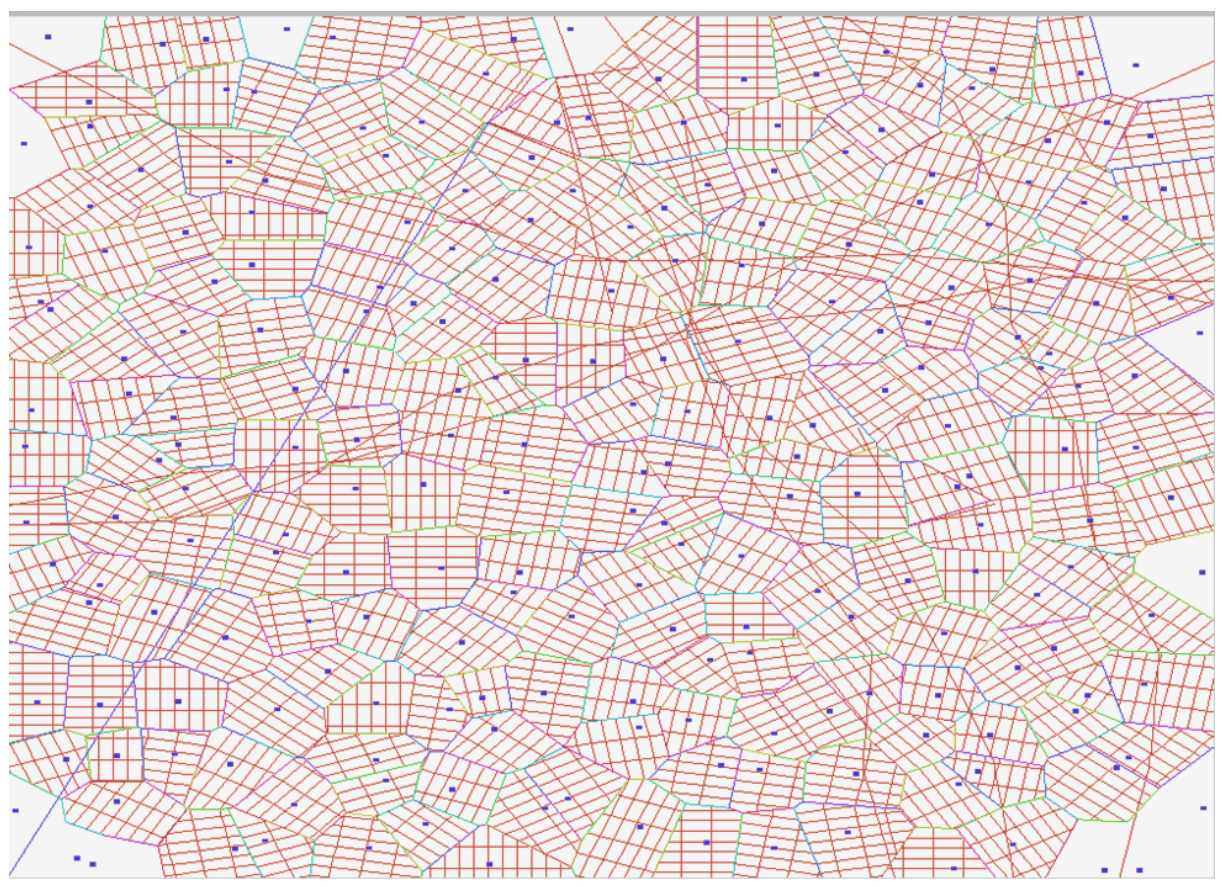

Figura 13. Through the insertion of avenues into de map, the whole models acquires an organization which mimics that happening in real modern cities.

\section{Conclusion}

Even though there are massive technological resources, most of city's authorities in world do not trace and record every situation and action happening in the city. In most cases this is caused by the lack of resources, although there are another crucial aspects restricting the pervasive recording of city situations and actions: privacy of citizens, old infrastructure, size of city, number of actors, etc.

Even though there are massive technological resources, most of city's authorities in world do not trace and record every situation and action happening in the city. In most cases this is caused by the lack of resources, although there are another crucial aspects restricting the pervasive recording of city situations and actions: privacy of citizens, old infrastructure, size of city, number of actors, etc.

Current paper presents a crucial stage in our research effort, because it focuses in the creation and representation of synthetic cities, which can be populated with all kinds agents representing citizens, vehicles, semaphores, pollution, rain, etc. and 
verify their interaction along time. Due to the academic essence of this research effort, we are developing all the tools an elements bottom-up.

According to the reviewed references, our proposal is one of a kind. This last utterance is far from vanity, it only claims that our approach and goals are novel and untreated previously. The ontological approaching is frequently used to match descriptions with patterns. Hence, we are looking for the production of patterns through an ontology. City patterns will be used as molds to produce virtual cities in computers' memory. When virtual cities are produced, they will be populated with diverse agents. Because of the aspects described in this paragraph, we have some constraints to present some testing results.

The Protégé did not manifest any oxymoron regarding the ontological model we produced as a general constructor for virtual cities. The ontology presented in this paper has the potential to model up diverse kinds of cities. Nevertheless, regarding any unconsidered aspect in current ontology; it would be very easy to include additional categories or relations in the ontology.

Future efforts in our research are aiming at the creation of the cyber-agents, as well as their inclusion to the city representation, the latter is focus of this paper.

\section{References}

Casillas, L., Daradoumis, T. \& Caballé, S. (2013). A Network Analysis Method for Selecting Personalized Content in e-Learning Programs. Complex, Intelligent, and Software Intensive Systems (CISIS), 2013 Seventh International Conference (pp. 407 411). Taichung, Taiwan: IEEE.

Courtat, T., Gloaguen, C., \& Douady, S. (2010). Mathematics and Morphogenesis of the City: A Geometrical Approach. arXiv: Electronic archive for physics, mathematics, computer science, nonlinear sciences, quantitative biology and statistics. Cornell University Library.

Davies, J., Duke, A. \& Sure, Y. (2004). OntoShare-An Ontology-based Knowledge Sharing System for virtual Communities of Practice. J. UCS, 10(3), 262-283. 
Döllner, J. \& Hagedorn, B. (2007). Integrating urban GIS, CAD, and BIM data by servicebased virtual 3D city models. R. e. al. (Ed.), Urban and Regional Data Management-Annual, 157-160.

Fortune, S. (1987). A sweepline algorithm for Voronoi diagrams. Algorithmica, 2(1-4), 153-174.

Gandy, M. (2005). Cyborg urbanization: complexity and monstrosity in the contemporary city. International journal of urban and regional research, 29(1), 26-49.

Ge, Y., Meng, R., Cao, Z., Qiu, X., \& Huang, K. (2014). Virtual city: An individual-based digital environment for human mobility and interactive behavior. Simulation 90(8), 917935.

Gruber, T. (1993). A Translation Approach to Portable Ontologies. Knowledge acquisition, v. 5, n. 2, 199-220.

Parish, Y., \& Müller, P. (2001). Procedural modeling of cities. SIGGRAPH '01 Proceedings of the 28th annual conference on Computer graphics and interactive techniques (pp. 301-308). New York, NY, USA: ACM.

Videira-Lopes, C., \& Lindstrom, C. (2012). Virtual Cities in Urban Planning: The Uppsala Case Study. Journal of theoretical and applied electronic commerce research, 7(3), 88-100.

Zhai, J., Wang, Q., \& LV, M. (2008). Application of XML Topic Maps to knowledge navigation and information retrieval for urban traffic information portal. Control Conference, 2008. CCC 2008. 27th Chinese (pp. 458 - 462). Kunming: IEEE.

\section{Notas biográficas:}

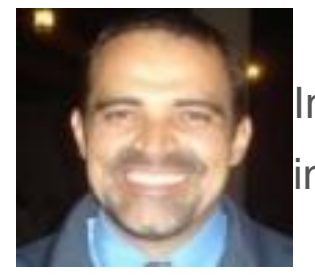

Dr. Luis Casillas holds a Ph.D. and a Master's Degree in Information and Knowledge Societies, as well as a Master's Degree in Information Systems and a B.Sc. in Informatics. He has been 
working as full-time professor for more than 20 years in the Computer Science Department from the University of Guadalajara (Mexico). He has published various papers and scientific chapters in diverse journals and books. He serves as member of the editorial board for a couple of journals, and reviewer for diverse journals and other scientific publications about: knowledge engineering, computer science and ICT in education. His research interests are: knowledge gathering and representation, bio-inspired systems, expert systems, complex networks analysis, and soft-computing.

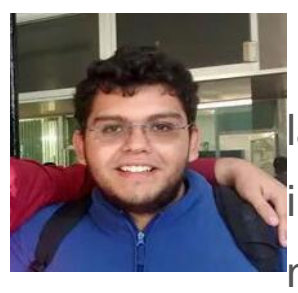

Gilberto Vargas En el 2011 inicié mi camino como estudiante de las ciencias computacionales participando en la olimpiada estatal de informática. Logré el primer lugar a nivel estatal y calificar a la fase nacional de la olimpiada, que se llevo a cabo en la ciudad de Cuernavaca, Morelos. Ahí obtuve una medalla de plata. En el 2012 volví a la olimpiada estatal pero esta vez como organizador. Hasta la fecha, mi función en la olimpiada es proponer problemas para los exámenes y entrenar a los mejores chicos que desean ir a la fase nacional. Ese mismo año ingresé a la licenciatura en la Universidad de Guadalajara y en Diciembre del 2015 egresé. Participe en el ICPC de la ACM desde el 2012 hasta el 2015 logrando calificar a la fase regional en todos los años. También junto a mi equipo, logramos el tricampeonato en el concurso de programación organizado por la ANIEI (2013-2015). En el 2013 realice una estancia de verano en el Cidetec de la UVM campus Guadalajara Sur, trabaje en un proyecto de tráfico urbano.

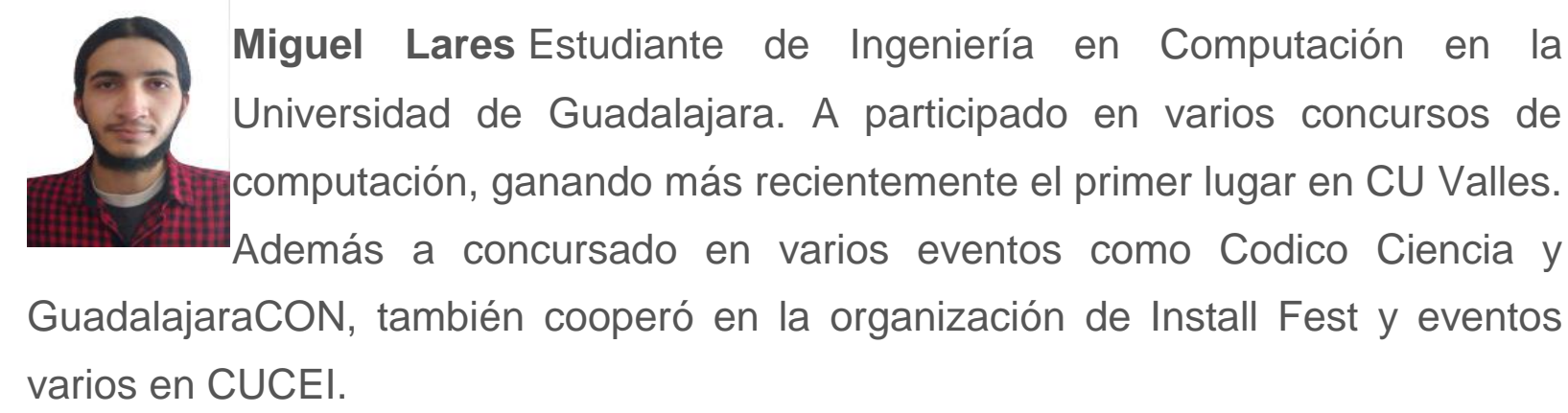




\section{(c) (1) (2) (2)}

Esta obra está bajo una licencia de Creative Commons Reconocimiento-NoComercial-Compartirlgual 2.5 México. 